\title{
Rapid analysis of risk assessment using developed simulation of chemical industrial accidents software package.
}

\begin{abstract}
The environmental consequences are defined as consequences of accidental release of hazardous substances to the natural environment. This release can lead to many hazards depending on the material stored. The consequences of these hazards to the environment are widespread and have significant importance to human communities living in the surroundings. The mathematical models are extremely useful tools to predict the impacts of chemical process accidents. The objective of this paper is to develop a software package for accident simulation and damage potential estimation. The software is coded in visual basic and is compatible with windows working environments. The software is called simulation of chemical industrial accident. This application is a comprehensive software package which can be integrated with geographical information system to predict and display the consequence of chemical hazards. The software is a user-friendly and effective tool for evaluating the consequences of major chemical accidents, process decision making for landuse planning, namely locating suitable hazardous installations, hazardous waste disposal areas and emergency response plan.
\end{abstract}

Keyword: Chemical process accident; Geographical information system; Mathematical models; Visual basic. 